\title{
Effects of MERTK Inhibitors UNC569 and UNC1062 on the Growth of Acute Myeloid Leukaemia Cells
}

\author{
YUKI KODA, MAI ITOH and SHUJI TOHDA \\ Department of Laboratory Medicine, Tokyo Medical and Dental University, Tokyo, Japan
}

\begin{abstract}
Background: MER proto-oncogene tyrosine kinase (MERTK) is a receptor tyrosine kinase that affects cancer cell proliferation. This study evaluated the effects of the synthetic MERTK inhibitors UNC569 and UNC1062 on in vitro growth of acute myeloid leukaemia (AML) cells. Materials and Methods: Four AML cell lines expressing MERTK were treated with UNC569 and UNC1062 and analyzed for cell proliferation, immunoblotting, and gene expression. The effects of MERTK knockdown were also evaluated. Results: Treatment with the inhibitors suppressed cell growth and induced apoptosis in all cell lines. OCI/AML5 and TMD7 cells, in which MERTK was constitutively phosphorylated by autocrine mechanisms, were highly susceptible to these inhibitors. The treatment reduced the phosphorylation of MERTK and its downstream signalling molecules, v-akt murine thymoma viral oncogene homolog 1 (AKT) and extracellular signal-regulated kinase (ERK). Similar effects were observed after MERTK knockdown. The inhibitors and the knockdown caused similar changes in mRNA expression. Conclusion: These MERTK inhibitors are potential molecular-targeted drugs for treating AML expressing constitutively phosphorylated MERTK.
\end{abstract}

MER proto-oncogene tyrosine kinase (MERTK) is a member of the TYRO3 protein tyrosine kinase (TYRO3)/AXL receptor tyrosine kinase (AXL)/MERTK family of receptor tyrosine kinases (collectively referred to as TAM). These kinases play important roles in cell growth in various organs and types of cancer. Binding of MERTK to its ligands, growth arrestspecific 6 (GAS6) and protein S, induces the phosphorylation of MERTK and its downstream signalling molecules, including v-akt murine thymoma viral oncogene homolog 1

This article is freely accessible online.

Correspondence to: Shuji Tohda, MD, Ph.D., Department of Laboratory Medicine, Tokyo Medical and Dental University, Yushima 1-5-45, Bunkyo-Ku, Tokyo 113-8519, Japan. Tel: +81 358035334, Fax: +81 358035629, e-mail: tohda.mlab@tmd.ac.jp

Key Words: MERTK, leukaemia, apoptosis.
(AKT) and extracellular signal-regulated kinase (ERK) (1). Overexpression of MERTK has been reported in acute myeloid leukaemia (AML) and acute lymphoblastic leukaemia (ALL) cells (2-4). However, the role of MERTK in leukaemia cell growth remains unclear.

Two small-molecule MERTK-selective inhibitors, UNC569 and UNC1062, have been developed (5-7) that inhibit the phosphorylation of MERTK by occupying its adenine pocket. The effects of UNC1062 are more specific to MERTK than those of UNC569. UNC569 was reported to suppress ALL cell growth in vitro (5). However, the effects of these inhibitors on AML cells and their molecular mechanisms have not been elucidated.

To elucidate the role of MERTK in the growth of AML cells and the molecular mechanism of action of these MERTK inhibitors, we evaluated the effects of these MERTK inhibitors on AML cell growth in vitro. To confirm the specificity of the effects, MERTK knockdown experiments using small interfering RNA (siRNA) were also performed. We aimed to determine whether MERTK inhibitors are candidates for use as novel molecularly-targeted drugs for the treatment of AML.

\section{Materials and Methods}

Cell lines and MERTK inhibitors. Four human AML cell lines were used in this study. The TMD7 cell line was established in our laboratory (8). The OCI/AML5 cell line was established at Ontario Cancer Institute (9). The THP-1 and HEL cell lines were obtained from the Health Science Research Resource Bank (Osaka, Japan). Normal lymphocytes from two healthy volunteers who provided informed consent were also used. UNC569 and UNC1062 were purchased from Calbiochem (San Diego, CA, USA) and Glixx Laboratories (Southborough, MA, USA), respectively. These inhibitors were dissolved in dimethyl sulfoxide (DMSO) at concentrations of $20 \mathrm{mM}$ and $3 \mathrm{mM}$, respectively.

Cell growth assay. Short-term cell growth was evaluated using a colorimetric WST-8 assay kit (Dojindo Laboratories, Kumamoto, Japan). Cells were cultured in 96-well plates in RPMI-1640 medium supplemented with $10 \%$ foetal bovine serum, with or without inhibitors, in a humidified atmosphere with $5 \% \mathrm{CO}_{2}$. After $72 \mathrm{~h}$, WST-8 and 1-methoxy-5-methylphenazinium methyl sulphate were added and the optical density (OD) was measured using an enzymelinked immunosorbent assay plate reader to determine the relative cell 
A
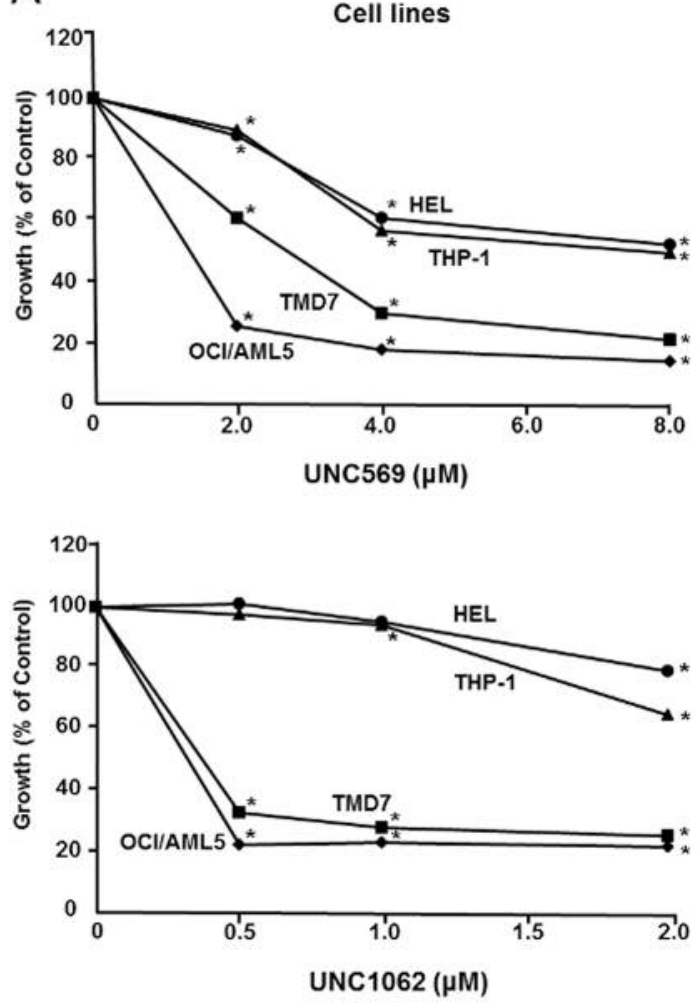

B
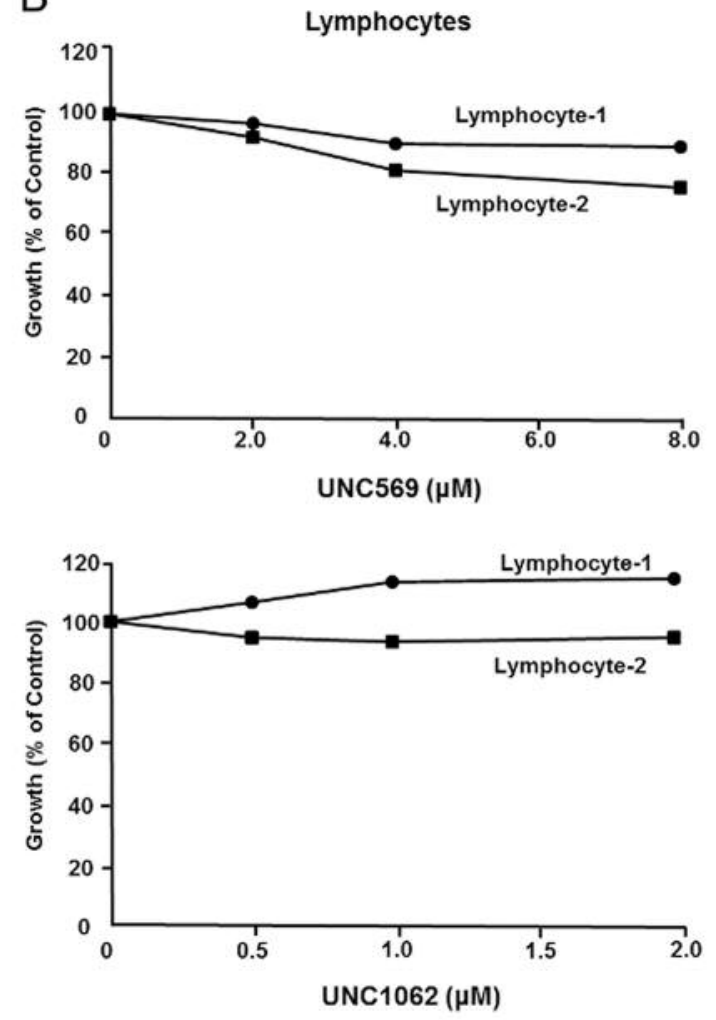

Figure 1. Effects of MER proto-oncogene tyrosine kinase inhibitors UNC569 and UNC1062 on growth of leukaemia cell lines (A) and lymphocytes from two healthy donors $(B)$. Cells were cultured with the indicated concentrations of the inhibitors for three days and cell growth was evaluated using a colorimetric assay. The results are expressed as a percentage of the mean optical density in inhibitor-treated cells normalized to that in control (dimethyl sulfoxide-treated) cells. *Significantly different at $p<0.05$ compared to the control.

number. Relative cell proliferation was calculated as the percentage of the mean OD value normalized to that of the control cells cultured with DMSO. Student's $t$-test was used to determine statistical significance of differences in growth. To examine cell morphology, the harvested cells were stained with May-Grünwald-Giemsa stain and observed on cytospin preparations under a microscope.

Apoptosis assay. Cells treated with the inhibitors for $48 \mathrm{~h}$ were stained with Annexin V-fluorescein isothiocyanate (FITC) and propidium iodide (PI), then analysed using a Navios cytometer (Beckman Coulter, Brea, CA, USA) to evaluate the induction of apoptosis.

MERTK knockdown by siRNA. MERTK knockdown by siRNA was performed to confirm the specificity of the effects of the inhibitors. Three different pre-designed MERTK siRNAs (Stealth siRNA ${ }^{\mathrm{TM}}$, HSS 116030, 116031, and 173654) were purchased from Life Technologies (Carlsbad, CA, USA). Stealth RNAi negative control duplex was used as a control. Cells were transfected with each siRNA using the Neon ${ }^{\mathrm{TM}}$ pipette tip chamber-based electroporation system (Life Technologies) and immediately transferred to the culture medium.

Immunoblot analysis. The lysates from the cells cultured with the inhibitors or siRNA were subjected to sodium dodecyl sulfatepolyacrylamide gel electrophoresis and analysed by immunoblotting with antibodies against MERTK, AKT, phospho-AKT, ERK,
phospho-ERK, caspase-3, cleaved caspase-3 (Cell Signaling Technology, Danvers, MA, USA), GAS6 (R \& D systems, Minneapolis, MN, USA), phospho-MERTK, protein S, and $\alpha$-tubulin (Abcam, Cambridge, MA, USA), which was used as a loading control. Immunoreactive bands were detected using a Pierce Enhanced Chemiluminescent Western Blotting Substrate (Pierce Biotechnology, Rockford, IL, USA). Each assay was repeated more than twice to ascertain qualitative reproducibility.

Microarray analysis. Microarray analysis was performed to assess the effects of the inhibitors and siRNA on comprehensive gene expression. OCI/AML5 and TMD7 cells were treated with UNC569, UNC1062, DMSO (solvent control), MERTK siRNA, or control siRNA for $24 \mathrm{~h}$. Total RNA was extracted using a High Pure RNA isolation kit (Roche Diagnostics, Mannheim, Germany) and used to prepare cyanine-3-labelled cRNA, which was hybridized to a SurePrint G3 Human GE microarray $8 \times 60 \mathrm{~K}$ v3 (Agilent Technologies, Santa Clara, CA, USA). The expression profile was analysed using Agilent Feature Extraction 11.5.1.1 software.

\section{Results}

Effects of MERTK inhibitors on cell growth. Treatment with UNC569 and UNC1062 suppressed growth in all AML cell 


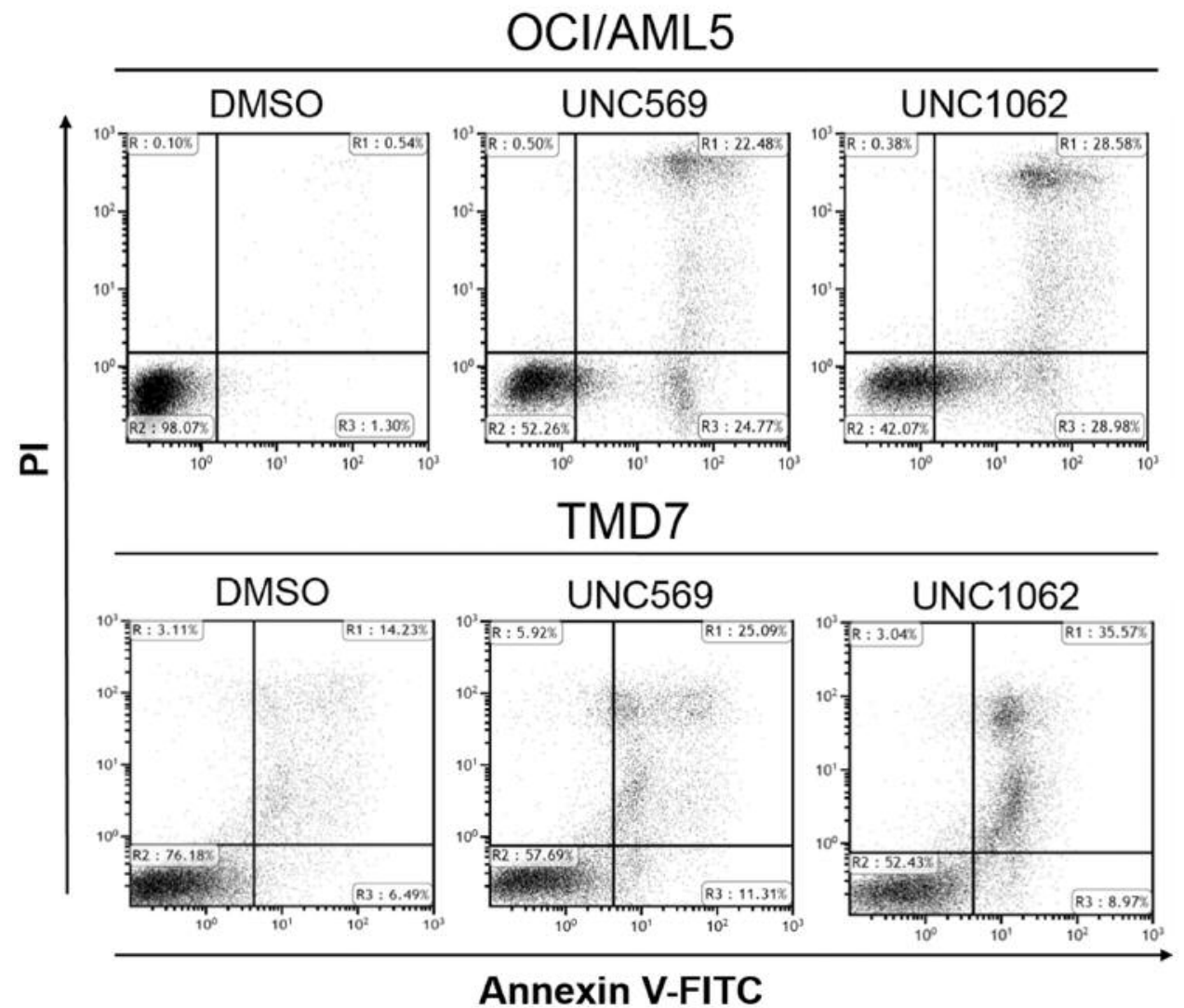

Figure 2. Apoptosis assay of acute myeloid leukaemia cells treated with MER proto-oncogene tyrosine kinase inhibitors UNC569 and UNC1062. Cells were cultured with $4 \mu \mathrm{M}$ UNC569 and $2 \mu \mathrm{M}$ UNC1062 for $48 \mathrm{~h}$, stained with annexin V-fluorescein isothiocyanate (FITC) and propidium iodide (PI), and analyzed for apoptosis using flow cytometry. DMSO: Dimethyl sulfoxide.

Table I. Microarray analysis of the effects of MER proto-oncogene tyrosine kinase (MERTK) inhibitors UNC569 and UNC1062, and MERTK siRNA on gene expression in leukaemia cell lines in vitro. Scale signals indicate the expression of each gene in dimethyl sulfoxide (DMSO)-treated control cells. $\mathrm{Log}_{2}$ ratios of mRNA expression in inhibitor-treated and MERTK siRNA-transfected cells were normalized to those in DMSO-treated and control siRNA-transfected cells, respectively.

\begin{tabular}{|c|c|c|c|c|c|c|c|c|}
\hline \multirow[t]{3}{*}{ Gene symbol } & \multicolumn{4}{|c|}{ OCI/AML5 } & \multicolumn{4}{|c|}{ TMD7 } \\
\hline & \multirow[t]{2}{*}{ Scale signal } & \multicolumn{3}{|c|}{$\log _{2}$ ratio } & \multirow[t]{2}{*}{ Scale signal } & \multicolumn{3}{|c|}{$\log _{2}$ ratio } \\
\hline & & UNC569 & UNC1062 & siRNA & & UNC569 & UNC1062 & siRNA \\
\hline MERTK & 151 & 0.90 & 1.21 & -3.58 & 1,171 & 0.27 & 0.37 & -2.63 \\
\hline TYRO3 & 11,436 & -0.27 & -0.43 & -0.13 & 507 & -0.11 & -0.47 & -0.18 \\
\hline$A X L$ & 750 & 0.33 & 0.25 & -0.14 & 860 & -0.32 & -0.31 & -0.02 \\
\hline GAS6 & 1,402 & -0.27 & -0.48 & 0.16 & 16 & NS & NS & 0.67 \\
\hline PROS1 & 2,091 & 0.65 & 0.87 & 0.04 & 7,230 & 0.37 & 0.16 & 0.08 \\
\hline$A D M$ & 1,590 & -4.10 & -3.87 & 1.91 & 26,235 & -1.28 & -1.11 & 0.10 \\
\hline$B C L 2$ & 17,191 & -0.06 & -0.23 & -0.20 & 1,844 & 0.33 & -0.19 & -0.46 \\
\hline$C C N D 1$ & 1,463 & -0.74 & -1.11 & -0.06 & 123 & -0.42 & -0.45 & -0.45 \\
\hline$I L 1 B$ & 80 & -1.52 & -2.30 & -1.79 & 858 & 0.70 & 0.70 & -1.46 \\
\hline$M Y C$ & 70.188 & -0.51 & -0.71 & 0.04 & 74,542 & -0.24 & 0.12 & 0.14 \\
\hline$R A G 1$ & 56 & 1.47 & 2.21 & 1.34 & 237 & 0.59 & 1.27 & 1.36 \\
\hline
\end{tabular}

NS: Not significantly expressed; TYRO3: TYRO3 protein tyrosine kinase; AXL: AXL receptor tyrosine kinase; GAS6: growth arrest-specific 6; PROS1: protein S; ADM: adrenomedullin; BCL2: B-cell leukaemia/lymphoma 2; CCND1: cyclin D1; IL1B: interleukin 1 beta; MYC: myelocytomatosis oncogene; RAG1: recombination activating 1 . 


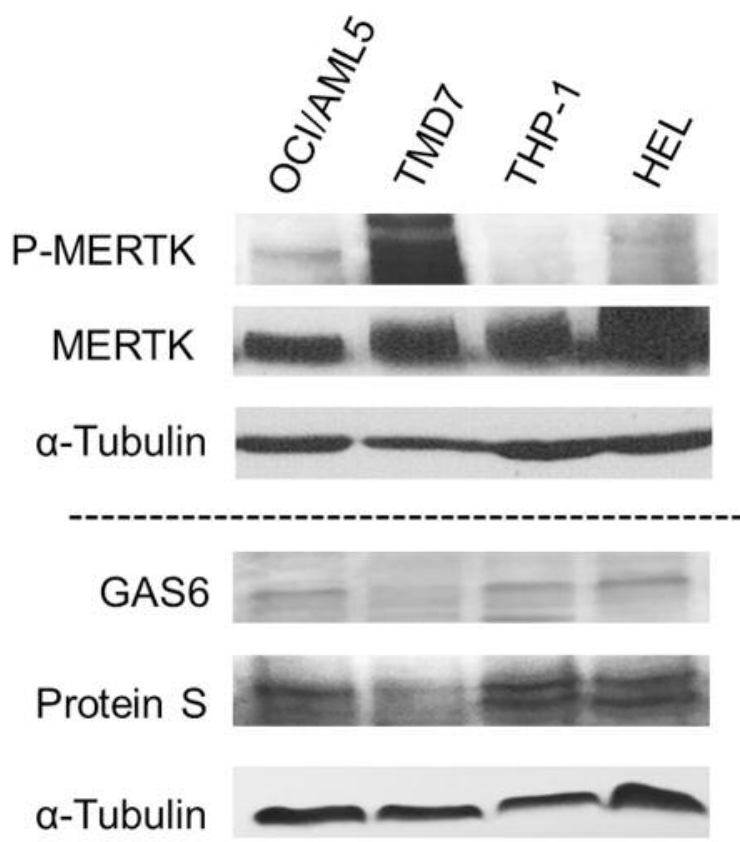

Figure 3. Expression of MER proto-oncogene tyrosine kinase (MERTK), phospho (P)-MERTK, growth arrest specific $6($ GAS6), protein $S$, and $\alpha$-tubulin in acute myeloid leukaemia cells analyzed by immunoblotting.

lines in a dose-dependent manner (Figure 1A). OCI/AML5 and TMD7 cells were more susceptible to the inhibitors than THP-1 and HEL cells. The treatment did not significantly affect the viability of normal lymphocytes in the range of concentrations tested (Figure 1B).

Cytospin preparations of cells treated with UNC569 and UNC1062 indicated there were apoptotic cells with nuclear condensation and apoptotic bodies in all AML cell lines (data not shown). Consistent with these results, the flow cytometric apoptosis assay revealed that the treatment increased the annexin- $\mathrm{V}$ positive fraction of OCI/AML5 and TMD7 cells (Figure 2). These results indicated that treatment with the inhibitors induced apoptosis.

MERTK, GAS6, and protein $S$ expression in AML cell lines. MERTK protein was expressed in all four cell lines (Figure 3). MERTK protein was constitutively phosphorylated in OCI/AML5 and TMD7 cells and weakly phosphorylated in HEL cells. GAS6 and protein S were strongly expressed in OCI/AML5, THP-1, and HEL cells, but weakly expressed in TMD7 cells. In the subsequent experiments to examine the effects of the inhibitors on signalling proteins, we used OCI/AML5 and TMD7 cells, in which MERTK was constitutively activated.

Effects of MERTK inhibitors on signalling proteins. Phosphorylation of MERTK in OCI/AML5 and TMD7 cells

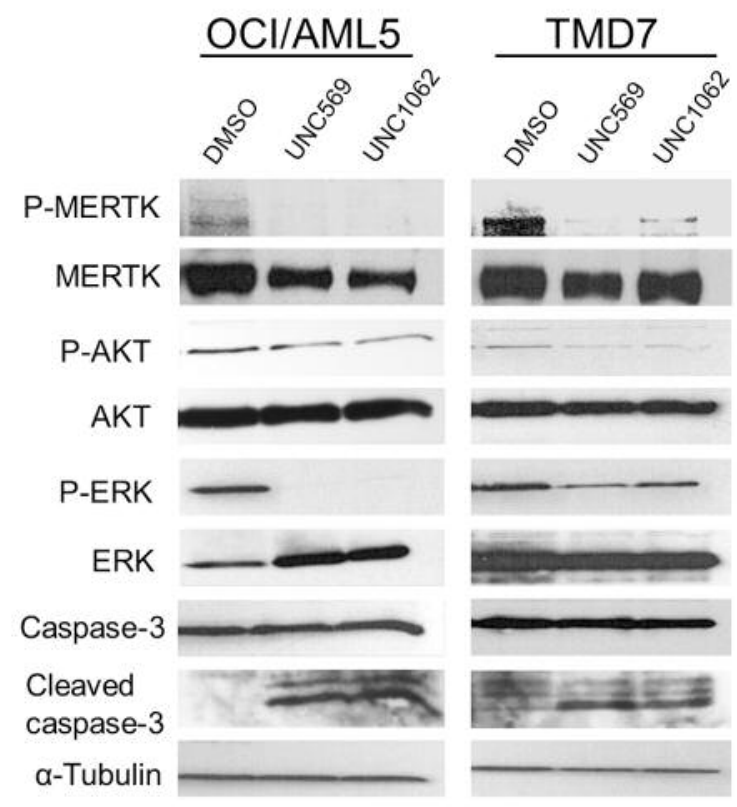

Figure 4. Expression and phosphorylation $(P)$ of MER proto-oncogene tyrosine kinase (MERTK) and down-stream signalling proteins in OCI/AML5 and TMD7 cells treated with MERTK inhibitors UNC569 and UNC1062. Cells were cultured with $4 \mu M$ UNC569 and $2 \mu M$ UNC1062 for $24 \mathrm{~h}$ and analysed by immunoblotting. Dimethyl sulfoxide (DMSO) was used as a vehicle control. (P-)AKT: (Phospho)-v-akt murine thymoma viral oncogene homolog 1; (P-)ERK: (phospho)extracellular signal-regulated kinase.

was suppressed by treatment with the inhibitors without significantly affecting the amount of MERTK protein (Figure 4). The treatment also suppressed phosphorylation of AKT and ERK, which are down-stream proteins of MERTK (1), and induced cleavage of caspase- 3 .

Effects of MERTK siRNA on cell growth and signalling proteins. To ascertain whether the above effects of the inhibitors were due to inhibition of MERTK function or offtarget effects, we performed MERTK knockdown experiments. Because siRNA HSS 173654 (5'-GCCGCAUUGCUAAG AUGCCUGUUAA-3') suppressed MERTK expression most potently among the three MERTK-specific siRNAs (data not shown), its effects on cell growth are shown in Figure 5. MERTK knockdown suppressed the growth of OCI/AML5 and TMD7 cells. In addition, MERTK knockdown suppressed the expression of MERTK and slightly suppressed the phosphorylation of AKT and ERK, without a decrease in AKT and ERK expression (Figure 6). MERTK knockdown also induced cleavage of caspase-3.

Microarray analysis. The effects of the inhibitors and MERTK siRNA on comprehensive gene expression were examined 

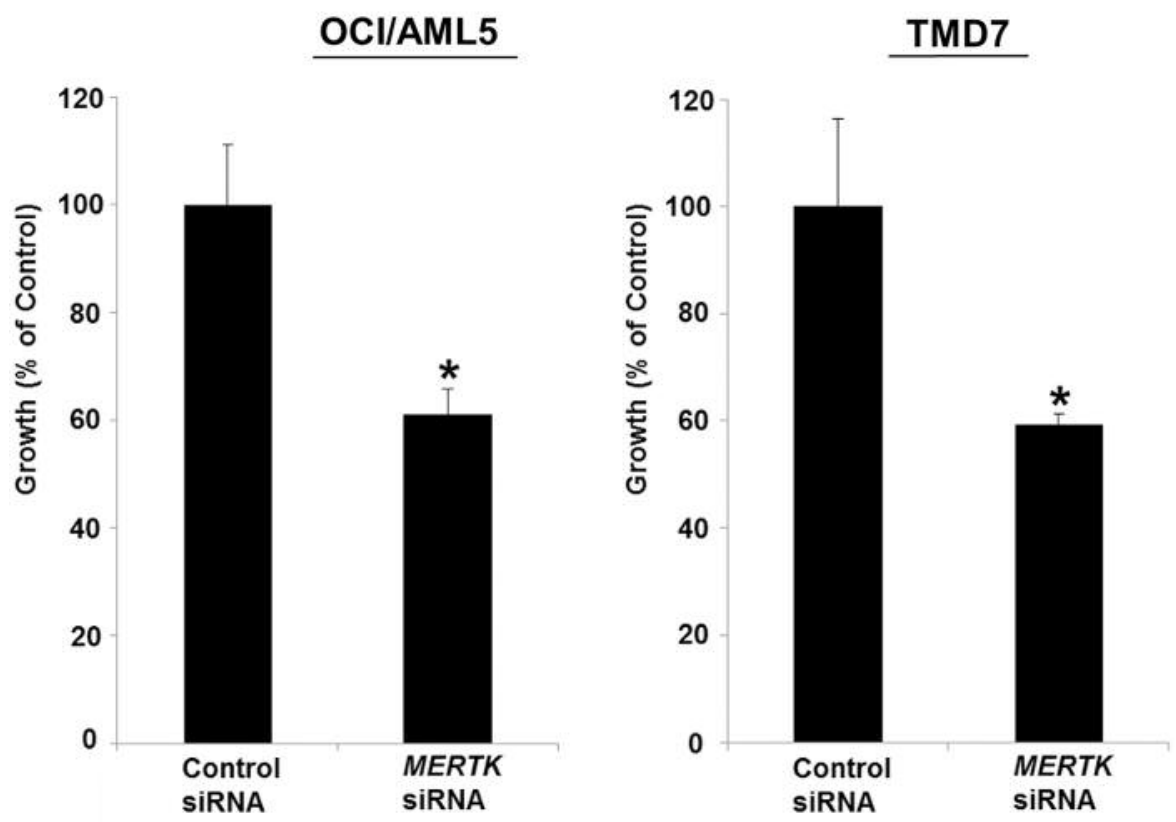

Figure 5. Effects of MER proto-oncogene tyrosine kinase (MERTK) knockdown on cell growth. The growth of OCI/AML5 and TMD7 cells transfected with $40 \mathrm{nM}$ of siRNA against MERTK was evaluated after 3 and 5 days, respectively, using a colorimetric assay. The results are expressed as a percentage of the mean optical density for MERTK-knockdown cells normalized to that in vector control cells. *Significantly different at $p<0.05$ compared to control.

using microarray analysis. The data from the representative genes are shown in Table I.

$M E R T K$ siRNA potently suppressed MERTK mRNA expression without affecting the expression of TYRO3 and $A X L$. Treatment with the inhibitors down-regulated some genes such as cyclin D1 (CCND1), but up-regulated others such as recombination activating 1 (RAGl). Adrenomedullin $(A D M)$ was down-regulated by both inhibitors, but up-regulated by MERTK siRNA in OCI/AML5 cells. Expression of GAS6 and PROS1, which encodes protein S, was not significantly affected by the inhibitors or siRNA.

\section{Discussion}

This study indicated that the MERTK inhibitors UNC569 and UNC1062 suppressed the growth of AML cells and induced their apoptosis. The suppressive effects of the inhibitors were more potent in OCI/AML5 and TMD7 cells in which MERTK was constitutively phosphorylated. A possible mechanism for the constitutive phosphorylation of MERTK in the cells was autocrine activation by the MERTK ligands GAS6 and protein $S$ produced by the leukaemia cells themselves. We confirmed that the use of a non-serum culture medium did not affect the intensity of their phosphorylation (data not shown). Therefore, GAS6 and protein S contained in the serum of the culture medium did not act as ligands. The reason that MERTK in THP-1 cells was not phosphorylated, even though the cells expressed GAS6 and protein $\mathrm{S}$, is not clear.
As indicated above, treatment with MERTK inhibitors suppressed phosphorylation of its down-stream proteins and induced cleavage of caspase-3. MERTK knockdown resulted in the same effects. These results suggest that the effects of the inhibitors were due to on-target effects.

Conversely, the changes in the expression of some genes caused by the inhibitors and those caused by MERTK knockdown were discrepant, although the discrepancies were not necessarily due to off-target effects because gene expression was examined only $24 \mathrm{~h}$ after inhibitor treatment and siRNA transfection. For example, $A D M$ expression was down-regulated by UNC569 treatment but up-regulated by siRNA transfection. ADM was previously reported to be involved in the proliferation of AML cells (10). Therefore, this effect of UNC569 may be an advantage of an anti-leukaemia drug. However, because ADM is also involved in vasodilation (11), administration of UNC569 might result in changes in blood pressure.

Recently, various novel TAM-targeting drugs have been developed and clinical trials using TAM-targeting drugs against leukaemia and various cancer types have been performed $(12,13)$. Considering the above effects of UNC569 and UNC1062 and the fact that they did not significantly affect the viability of normal lymphocytes, these inhibitors may be useful as novel molecularly-targeted drugs against AML cells, particularly AML cells in which MERTK is constitutively activated. Before their clinical use, further investigation for the possibility of adverse effects due to their 


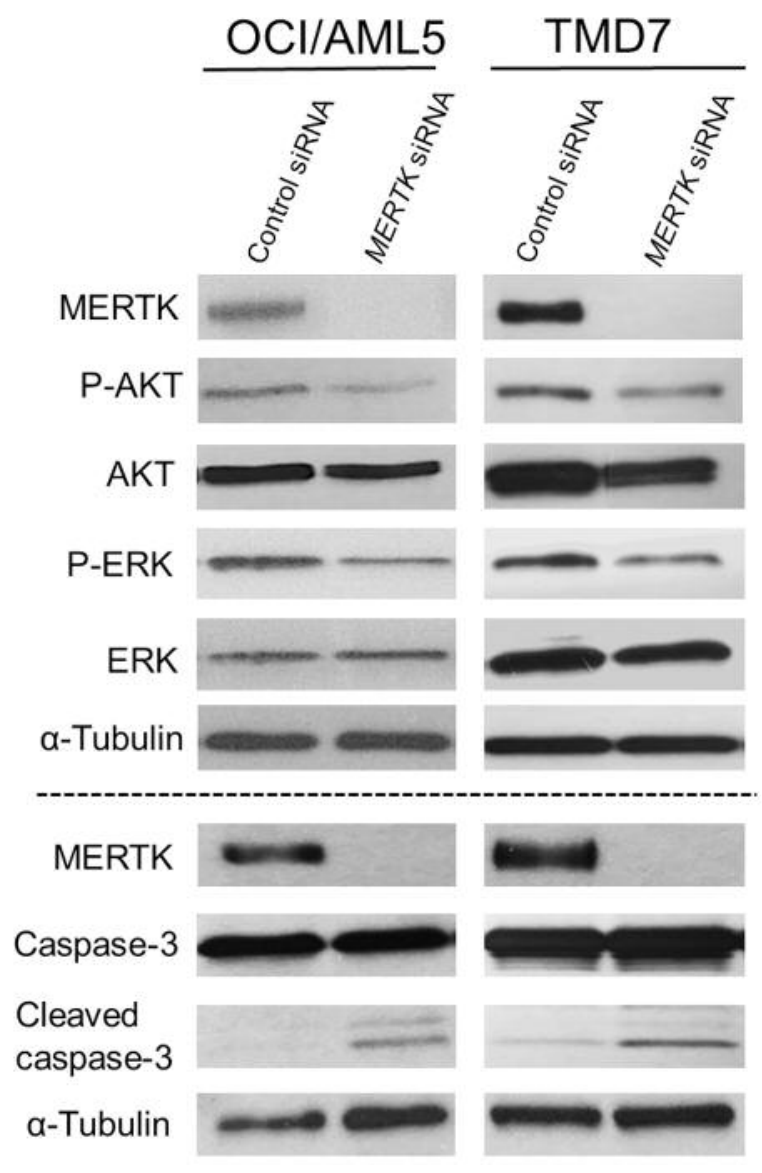

Figure 6. Effects of MER proto-oncogene tyrosine kinase (MERTK) knockdown on the expression and phosphorylation $(P)$ of MERTK and down-stream proteins. OCI/AML5 and TMD7 cells were transfected with $80 \mathrm{nM}$ siRNA or $40 \mathrm{nM}$ siRNA, respectively. After 2 days, cells were harvested for immunoblotting. (P-)AKT: (Phospho)-v-akt murine thymoma viral oncogene homolog 1; (P-)ERK: (phospho)-extracellular signal-regulated kinase.

off-target and on-target effects on normal cells and organs is required. Moreover, development of drug-sensitivity tests to predict validity and select appropriate AML cases are required.

\section{Acknowledgements}

The Authors thank Mr. Yuki Yokoi for his experimental help and discussion. This study was supported in part by a Grant-in-Aid for Scientific Research (C) from the Japan Society for the Promotion of Science (No. 26460669).

\section{References}

1 Huey MG, Minson KA, Earp HS, DeRyckere D and Graham DK: Targeting the TAM receptors in leukemia. Cancers 8: E101, 2016.

2 Lee-Sherick AB, Eisenman KM, Sather S, McGranahan A, Armistead PM, McGary CS, Hunsucker SA, Schlegel J,
Martinson H, Cannon C, Keating AK, Earp HS, Liang X, DeRyckere D and Graham DK: Aberrant MER receptor tyrosine kinase expression contributes to leukemogenesis in acute myeloid leukemia. Oncogene 32: 5359-5368, 2013.

3 Linger RM, Lee-Sherick AB, DeRyckere D, Cohen RA, Jacobsen KM, McGranahan A, Brandão LN, Winges A, Sawczyn KK, Liang X, Keating AK, Tan AC, Earp HS and Graham DK: MER receptor tyrosine kinase is a therapeutic target in pre-B-cell acute lymphoblastic leukemia. Blood 122: 1599-1609, 2013.

4 Brandao LN, Winges A, Christoph S, Sather S, Migdall-Wilson J, Schlegel J, McGranahan A, Gao D, Liang X, Deryckere D and Graham DK: Inhibition of MerTK increases chemosensitivity and decreases oncogenic potential in T-cell acute lymphoblastic leukemia. Blood Cancer J 3: e101, 2013.

5 Christoph S, Deryckere D, Schlegel J, Frazer JK, Batchelor LA, Trakhimets AY, Sather S, Hunter DM, Cummings CT, Liu J, Yang C, Kireev D, Simpson C, Norris-Drouin J, Hull-Ryde EA, Janzen WP, Johnson GL, Wang X, Frye SV, Earp HS 3rd and Graham DK: UNC569, a novel small-molecule mer inhibitor with efficacy against acute lymphoblastic leukemia in vitro and in vivo. Mol Cancer Ther 12: 2367-2377, 2013.

6 Liu J, Yang C, Simpson C, Deryckere D, Van Deusen A, Miley MJ, Kireev D, Norris-Drouin J, Sather S, Hunter D, Korboukh VK, Patel HS, Janzen WP, Machius M, Johnson GL, Earp HS, Graham DK, Frye SV and Wang X: Discovery of novel small molecule MER kinase inhibitors for the treatment of pediatric acute lymphoblastic leukemia. ACS Med Chem Lett 3: 129-134, 2012.

7 Liu J, Zhang W, Stashko MA, Deryckere D, Cummings CT, Hunter D, Yang C, Jayakody CN, Cheng N, Simpson C, NorrisDrouin J, Sather S, Kireev D, Janzen WP, Earp HS, Graham DK, Frye SV and Wang X: UNC1062, a new and potent MER inhibitor. Eur J Med Chem 65: 83-93, 2013.

8 Tohda S, Sakano S, Ohsawa M, Murakami N and Nara N: A novel cell line derived from de novo acute myeloblastic leukaemia with trilineage myelodysplasia which proliferates in response to a Notch ligand, Delta-1 protein. Br J Haematol 117: 373-378, 2002.

9 Tohda S, Curtis JE, McCulloch EA and Minden MD: Comparison of the effects of all-trans and cis-retinoic acid on the blast stem cells of acute myeloblastic leukemia in culture. Leukemia 6: 656661, 1992.

10 Di Liddo R, Bridi D, Gottardi M, De Angeli S, Grandi C, Tasso A, Bertalot T, Martinelli G, Gherlinzoni F and Conconi MT: Adrenomedullin in the growth modulation and differentiation of acute myeloid leukemia cells. Int J Oncol 48: 1659-1669, 2016.

11 Krzeminski K: The role of adrenomedullin in cardiovascular response to exercise - a review. J Hum Kinet 53: 127-142, 2016.

12 Lee-Sherick AB, Zhang W, Menachof KK, Hill AA, Rinella S, Kirkpatrick G, Page LS, Stashko MA, Jordan CT, Wei Q, Liu J, Zhang D, DeRyckere D, Wang X, Frye S, Earp HS and Graham DK: Efficacy of a MER and FLT3 tyrosine kinase small molecule inhibitor, UNC1666, in acute myeloid leukemia. Oncotarget 6: 6722-6736, 2015.

13 Wu G, Ma Z, Hu W, Wang D, Gong B, Fan C, Jiang S, Li T, Gao $\mathrm{J}$ and Yang Y: Molecular insights of GAS6/TAM in cancer development and therapy. Cell Death Dis 8: e2700, 2017.

Received September 12, 2017 Revised October 29, 2017 Accepted October 31, 2017 